\title{
Potential Uses of Web 2.0 Tools for Library Client Communication and Relationship Development
}

\author{
Jadranka Lasic-Lazic, ${ }^{1}$ Mihaela Banek Zorica ${ }^{2}$ and Goran Bubas $^{3}$ \\ ${ }^{1}$ University of Zagreb, Faculty of Humanities and Social Sciences, Zagreb, Croatia \\ ${ }^{2}$ University of Zagreb, Faculty of Humanities and Social Sciences, Zagreb, Croatia \\ ${ }^{3}$ University of Zagreb, Faculty of Organization and Informatics, Varazdin, Croatia
}

Abstract: In this paper, the potential uses of Web 2.0 technologies for the improvement of communication with library clients are examined. Wikis, blogs, RSS, mash-ups and other Web 2.0 tools and services can assist librarians in their efforts to present information online and better connect with their clients, especially the younger generations of Internet users. In three different studies we investigated (1) the familiarity of informatics students with Web 2.0 tools, (2) the computer literacy and Internet use by librarians in higher-education institutions, as well as their assessment of the potential uses of various Web 2.0 tools for interaction with the clients of their library, and (3) the use of Web 2.0 tools on the websites of public libraries in Croatia.

Keywords: Library 2.0, Web 2.0, library service, communication, user satisfaction

\section{Introduction}

According to the Library 2.0 concept, library service is oriented "towards the needs and expectations of library users" and "makes information available wherever and whenever the user requires it" (Lepik, 2007). Libraries should exploit the new possibilities for interaction with clients that the Internet/web offers and use novel methods and channels to design and deliver their services, keeping in mind the concepts of customer relationship management and relationship marketing (see Wang, 2007). Library 2.0 is a reaction to the webbased developments in ICT and the widespread use of social software (see Curran et al., 2007). To improve communication with their users, libraries can use Web 2.0 tools and services like wikis, blogs, RSS, mash-ups, or even Facebook (Alsbjer, 2008). The use of Web 2.0 tools can enhance the library's communication with the public, the involvement of the community in the planning and evaluation of library services, the sharing of users' knowledge, as well as the overall experience of users (Stephens and Collins, 2007). The use of Web 2.0 tools may also better fulfil the expectations of the growing population of digital natives who "want to create, remix and share content" (Foo \& Ng, 2008).

The theoretical explanations of the Library 2.0 concept should take into account that it (1) reflects user-centeredness; (2) is related to multi-media environments and communication channels; (3) provides the customer with the experience of social presence and enables interaction with librarians and other users; (4) is communally innovative, i.e. works as a community service adaptable to change and allows users to initiate and guide this change of services related to seeking and utilizing information (see Manes, 2006). Reflecting on the development of libraries' web services at the University of Houston, Coombs (2007) outlined the fundamentals of Web 2.0 that were used as guidelines for this effort: (1) decentralization of content creation; (2) orientation toward the use of "small pieces" of different technologies for the library web pages like wikis, blogs, and content management systems; (3) "perpetual beta", i.e. graduate 
introduction of various innovative technologies and services, their testing by small groups of library staff before implementation, evaluation and redesign based on feedback from users; (4) "remixable content" that can be integrated into the websites of other libraries or university departments; (5) encouragement given to users to contribute as content creators; (6) ensuring rich user experience with multimedia, potential for interaction, customization, and personalization.

However, in a study of ICT competencies of students enrolled in school library media programs in the USA, it was found that $50 \%$ or more were not familiar with or seldom used Web 2.0 related tools like podcasts, wikis, blogs, RSS feeds, and social bookmarking (Hanson-Baldauf \& Hughes Hassel, 2009). Another study of Web 2.0 use by librarians in Israel revealed that $26 \%$ rated themselves as having a low level of computer expertise, and that library managers use Web 2.0 more often than ordinary librarians, recognize better the potential of such technologies, and understand that by using them the libraries may attract different types of users (Aharony, 2009).

Even though both large and small libraries tend to use Web 2.0 tools, in the United States they are more frequently used by successful libraries (see Lietzau, 2008). Decision-makers may find it important to include the use of Web 2.0 technologies in library services and develop training programs for librarians (Al-Fadhli, 2008), especially because such training programs have already been successfully implemented (Titangos and Mason, 2009).

This paper presents an overview of the potential uses of various Web 2.0 tools for the improvement of library services and for the online interaction of libraries with their clients. Data on the use of Web 2.0 tools by students of Informatics are also provided to support the argument that library services based on Web 2.0 tools can find potential users. In addition, a survey was also performed among librarians who work in higher education institutions to investigate their use of Web 2.0 tools and their assessment of the potential usefulness and applicability of Web 2.0 tools in their libraries. Finally, the websites of public libraries in cities and towns in Croatia were analyzed regarding the use of Web 2.0 tools.

\section{Problem and Hypotheses}

The main problem of this study was to investigate the potential of introducing Web 2.0 tools into Croatian libraries. Three different small-scale studies were conducted to at least partly respond to this problem. The goal of the first study was to determine how familiar students of Informatics are with Web 2.0 technologies and how often they use them. The intention of the second study was to investigate computer literacy, the use of the Internet and of Web 2.0 tools, and also to assess the potential usefulness and applicability of Web 2.0 tools by librarians who work in higher education institutions. The goal of the third study was to investigate the implementation of Web 2.0 tools on the websites of public libraries in Croatia.

According to the previously stated problem and research goals, the following hypotheses were formulated.

- H1: Students of informatics are familiar with Web 2.0 tools.

- H2a: Librarians at higher education institutions have sufficient computer/information literacy to use Web 2.0 tools.

- H2b: Librarians at higher education institutions find Web 2.0 tools to be 
potentially useful in their libraries.

- H3: Public libraries in Croatia use Web 2.0 tools on their websites for interaction with clients/users.

\section{Method}

A survey method was used in the first study of the use of Web 2.0 tools by students of Informatics. The subjects of this research were 285 students of the University of Zagreb, Croatia (20-25 years of age; $75 \%$ male and $25 \%$ female). The students were asked to rate their knowledge of various Web 2.0 tools using a 1-5 point Likert-type scale (5 - excellent knowledge; 4 - good knowledge; 3 - average knowledge; 2 - limited knowledge; 1 - not familiar).

The 51 subjects in the second study were librarians who worked in higher education institutions in Croatia. They had 1 to 35 years of work experience in a library (14 years on average) and $92 \%$ of them were female. All of them had Internet access at work and $92 \%$ of them stated that their clients could also access the Internet from their library. As many as $96 \%$ of the librarians accessed the Internet at work for one or more hours per day (it must be noted that $78 \%$ of the librarians stated that they used the Internet from work for as many as three or more hours per day). A survey was performed on this set of subjects to determine their level of computer/Internet literacy, their familiarity with popular Internet and Web 2.0 tools, and also their assessment of the potential of Web 2.0 tools to interact with the clients of their library.

In the third study an examination was performed on the websites of public libraries of 124 cities and towns in Croatia. Library websites were found in 41 cities and towns and they were searched for the use of Web 2.0 tools. In addition, the libraries with websites were contacted by telephone to check if Web 2.0 tools were used by librarians to interact with clients/users.

\section{Results}

In our first study, the survey of students of Informatics regarding their use of Web 2.0 tools revealed that most of them were familiar with popular tools/services like wikis, blogs, YouTube and MySpace/Facebook (see Table 1). However, less than $50 \%$ had more than scarce knowledge of a popular website for the exchange of photographs named Flickr, or a known social bookmarking site named Delicious, and of an even more popular online virtual world Second Life. Only a rather small percentage of students of Informatics stated that they were familiar with other Web 2.0 tools and services like those for creating web forms (JotForm), the placing of audio comments on presentation slides (Slidestory), adding text balloons as comments for video files (Bubbleply), the tagging of video and audio-recordings (Veotag), drawing mind maps (Bubbl.us), creating cartoon strips from Flickr photographs (Bubblr), and drawing block diagrams (Gliffy). Since students of Informatics have a high level of computer/Internet literacy and knowledge of Internet-based tools and services, it can be concluded that for the general public and less ICT literate students at college only the most popular Web 2.0 tools can be recommended for use by libraries. The use of less-known Web 2.0 tools for interaction with clients/users should perhaps be combined with online/offline tutorials, training sessions, or workshops. 
Table 1. Percentage of students of Informatics who stated that they had average, good or excellent knowledge of a specific Web 2.0 tool $(\mathrm{N}=285)$

\begin{tabular}{|l|l|c|}
\hline WEB 2.0 TOOL & FUNCTION & $\mathbf{\%}$ \\
\hline YouTube & web publishing and exchange of video files & 95.4 \\
\hline Wiki & web publishing & 90.2 \\
\hline Blog & online diary & 88.8 \\
\hline MySpace/Facebook & social networking & 78.2 \\
\hline Flickr & exchange and search of photographs & 47.7 \\
\hline Second Life & 3D online virtual world & 32.6 \\
\hline Delicious & social bookmarking & 28.4 \\
\hline JotForm & web forms & 22.6 \\
\hline Slidestory & placing of audio comments on presentation slides & 16.1 \\
\hline Bubbleply & adding text balloons as comments for video files & 10.9 \\
\hline Veotag & tagging of video and audio-recordings & 10.9 \\
\hline NoteMesh & exchange of notes by students on the same courses & 9.5 \\
\hline Bubbl.us & mind maps & 8.1 \\
\hline Bubblr & creation of cartoon strips from Flickr photographs & 4.9 \\
\hline Gliffy & block diagrams & 4.2 \\
\hline
\end{tabular}

In our second study, the level of computer literacy of librarians from higher education institutions was investigated (a convenience sample of 51 librarians was used). It was found that all of them stated that they had an average or higher level of knowledge of the use of the MS Windows operating system and the text processor MS Word. As many as $80 \%$ stated that they had average or better knowledge of MS Excel. However, only 49\% stated that they had average or better knowledge of creating web pages, and $30 \%$ or less had knowledge of how to write a text in a wiki or a blog. Even though $84 \%$ of librarians stated that they read an online forum at least once a week, only $28 \%$ wrote a text in an online forum once a week or more often. Up to $69 \%$ of librarians stated that they read a blog at least once a week, but only $14 \%$ reported that they actually wrote a text in a blog once a week or more often. Similar percentages were reported for reading a wiki and writing in one. Finally, only $20-25 \%$ of librarians reported using instant messaging (ICQ), Skype, or MySpace/Facebook at least 1 to 2 times a week.

In this second study, the librarians from higher education institutions were also asked to assess how useful specific Web 2.0 technologies could be and how applicable they would be to improve their work with the users/clients of their library. The rating of usefulness/applicability was performed on a 1-5 Likerttype scale (1 - totally useless / non-applicable; 2 - mostly useless / difficult to apply; 3 - both useful and useless / possibly applicable; 4 - useful / mostly applicable; 5 - very useful / applicable). The respondents could also indicate that they could not perform the rating of a specific Web 2.0 tool. The results of the rating of Web 2.0 tools are presented in Figure 1 (the average ratings were calculated from 30-48 responses of librarians, depending on their ability to perform the rating). 


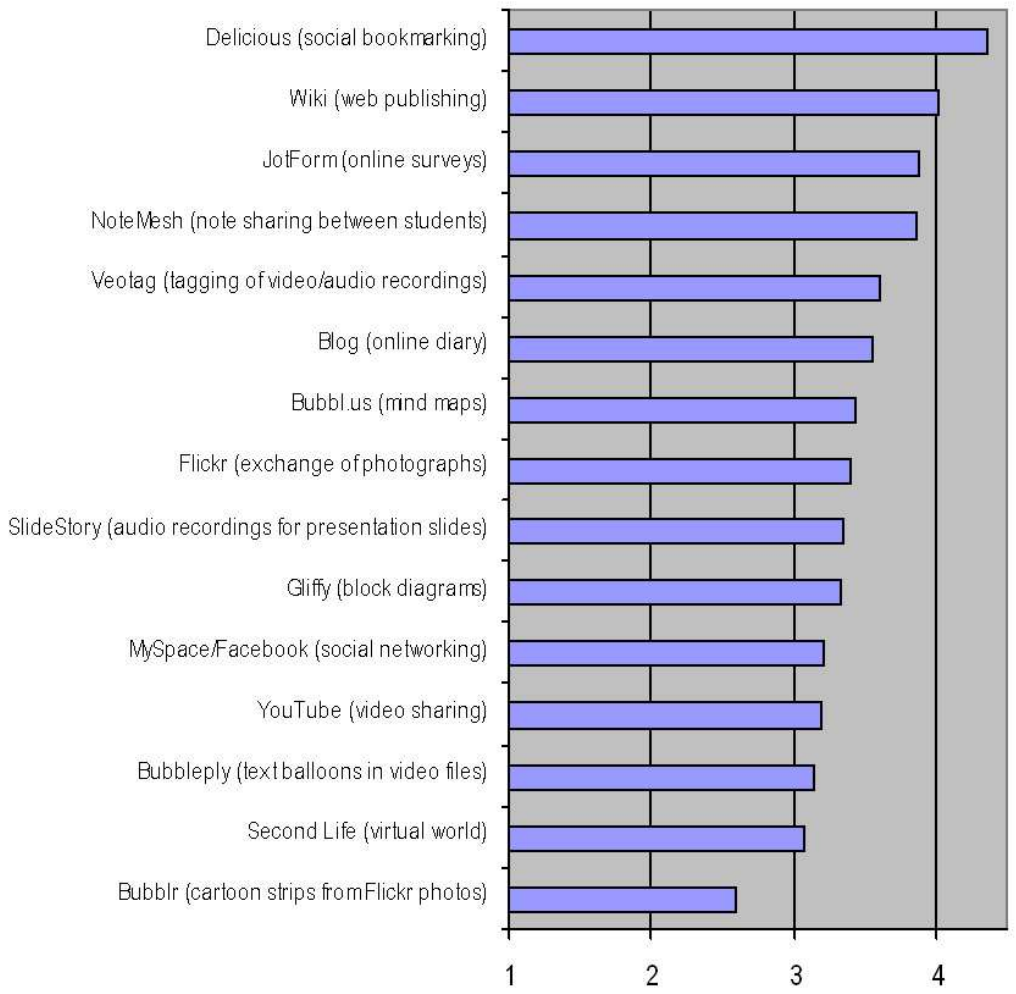

Figure 1. Average ratings by librarians of the potential usefulness and applicability of Web 2.0 technologies in higher education institutions ( 1 - totally useless / non-applicable; 5 very useful / applicable)

According to the results of our survey, the social bookmarking tool (Delicious) received the highest average rating for potential usefulness/applicability. The average rating of the use of a wiki tool was also rather high, as was the use of tools for online surveys (JotForm) and exchange of notes taken by students attending the same courses (NoteMesh). It must be noted that the librarians gave on average a rating of 3 or above to most of the other Web 2.0 tools. Therefore, at least some potential use/applicability of the Web 2.0 tools that are listed in Figure 1 was recognized by the librarians from higher education institutions.

Finally, the results of the third study were rather discouraging regarding the use of Web 2.0 tools on the websites of public libraries in Croatia. As can be concluded from the data presented in Table 2, most of the public libraries of cities and towns in Croatia had only one web page or almost no web presence at all (except perhaps some general information on the website of their city/town). There was a total of 44 libraries that had a website of more than one webpage and on those websites no use of Web 2.0 tools was noticed during the examination of the respective web pages. However, a subsequent telephone inquiry revealed that two public libraries used a blog and one used a wiki, although not on their websites. 
Table 2. Public libraries of cities and towns in Croatia with websites, and their use of Web 2.0 tools

\begin{tabular}{|l|c|}
\hline Web presence and use of Web 2.0 tools by public libraries & Number \\
\hline Libraries without a web page / website & 19 \\
\hline Libraries with only one web page & 61 \\
\hline Libraries with a website & 44 \\
\hline Libraries with a website that used a Web 2.0 tool (wiki, blog) & 2 \\
\hline
\end{tabular}

\section{Discussion}

The survey performed in our first study revealed that the majority of the students of Informatics were familiar only with the most popular Web 2.0 tools such as wikis, blogs, and social networking sites. Many tools which are potentially useful to students and educators (NoteMesh, Bubbl.us, Bubblr, Gliffy) were known by less than $10 \%$ of students (the related findings are presented in more detail in a paper by Orehovacki et al., 2008). Therefore, the first hypothesis could only partly be confirmed. However, in one university course which used Web 2.0 tools for the design of e-learning activities it was found that the students of Informatics could learn in 15 to 30 minutes to use most of these tools (e.g. wiki, blog, JotForm, Slidestory, Bubbleply, Veotag, NoteMesh, Bubbl.us, Bubblr, Gliffy). This indicates that perhaps it would not be difficult to train librarians in the use of selected Web 2.0 tools to present information and improve their communication over the website of the library, or to use an alternative to an official website (i.e. use something else than a content management system). For instance, those libraries that could not afford to have a website could present their information over a Croatian version of Wikipedia, interact with the public through a blog, perform online surveys with JotForm, present their collections with SlideStory or Veotag, interact with children using Bubbleply of Bubblr, help students learn for specific courses using NoteMesh, or explain specific concepts/ideas or procedures/processes with Bubbl.us or Gliffy.

Our second survey of 51 librarians at higher education institutions indicated that most have basic computer skills and use the Internet at least several hours per day. In addition, most of them read content on a wiki or blog at least once a week. On average, those librarians believed that certain Web 2.0 tools could be useful and applicable in their libraries (for instance, Delicious, wiki, JotForm, Notemesh). It must be noted that, when average ratings are considered, none of the Web 2.0 tools listed in Figure 1 was excluded from this possibility. Because of their rather high level of basic computer literacy, it can be taken that librarians at higher education institutions have sufficient computer/information literacy to use Web 2.0 tools and that they find Web 2.0 tools to be of potential usefulness in their libraries. Thus, hypotheses $\mathrm{H} 2 \mathrm{a}$ and $\mathrm{H} 2 \mathrm{~b}$ can be accepted.

However, the third hypothesis of our study could not be confirmed due to the fact that the majority of public libraries in Croatia do not use Web 2.0 tools for interaction with their clients/users. Only a few libraries reported using such tools, but separately of their official web pages. It must be noted that Web 2.0 tools were also not found on the websites of the libraries of 26 research institutes in Croatia, on the websites of 6 university libraries, or on the web pages of 15 museum libraries. 


\section{Educating the librarians}

The conducted studies and the related results confirm the need to modify the current library curriculum at the Department of Information Sciences, Faculty of Humanities and Social Sciences, University of Zagreb. Improvements have been applied in our part-time curricula intended for students who are already working in public or school/university libraries. This was done mainly since these professionals could benefit from this knowledge and instantly implement the methods and examples learned. Two new courses were introduced: Information literacy and E-learning, both focusing on the role of librarians in this new informational and educational environment. The objective of these courses is to give students insight into both the theory (information literacy course) and the practical (e-learning course) application of Web 2.0 tools and services in the transformed learning environment. The information literacy course was more oriented towards the theory of information literacy, the transformation of the web environment and its implementation in various library types and workplace environments. On the other hand, the e-learning course was more practically oriented towards new learning modes and different educational environments, focusing on the position and role of the librarians. Courses are offered in two modes: as distance learning and as an on-site course mainly based on using our e-learning system OMEGA (based on Moodle LMS) and the virtual faculty space in the virtual world - Second Life.

The main motivator for these courses is to offer on-hand experience, both from the student's point of view and from the teacher's position, thereby providing the librarians with basic knowledge of tools and services as well as experience in working with the technology that the majority of their users are familiar with. In order to create a successful Library 2.0 environment, we need to give both current and future librarians the theoretical background and practical exercises which can be carried out in attending such classes and workshops. Users who have actively participated in using new technology in learning and training are able to assess all the benefits and shortcomings of introducing new tools and teaching methods in their work environment. As librarians have a mission to provide their users with information and to respond to their users' information needs, this seems one of the best ways to do so.

\section{Conclusion}

Web 2.0 tools and services have huge potential. This potential is partially recognized and used by students and library users but it is still not utilized by librarians themselves. The majority of public libraries are present in the Web 1.0 world but still need to include and adapt their services in the Web 2.0 environment. Although one cannot say that librarians lack basic computer literacy and skills for the Web 2.0 context, they perhaps lack agility in implementing new technologies and services. Introducing librarians to the potential of various Web 2.0 tools could be one of the solutions to help them adopt these new services. This could be accomplished by offering training programs for librarians in order to help them meet their users' needs. Only educated librarians who are knowledgeable in the usage of social networking tools and services can promote these services to their users who are, in higher education libraries, both students and teachers. The full potential of Web 2.0 could then be brought out in the whole educational environment, i.e. in the learning and research process. 


\section{References}

Aharony, N. (2009). Web 2.0 use by librarians, Library \& Information Science Research, Vol. 31, No. 1, 29-37.

Al-Fadhli, M. S. (2008) Web $2.0+$ Library = Library $2.0 /$ What is Library 2.0? [Unpublished $\begin{array}{llllll}\text { Report], } & \text { Retrieved } & \text { on } & 10 & \text { January } & 2009\end{array}$ from http://eprints.rclis.org/12679/1/Web $2.0 \% 26$ Library 2.0.pdf

Alsbjer, P. (2008). Interaction: Anything goes 2.0. Scandinavian Public Library Quarterly, Vol. 41, No. 2, 6-9.

Casey, M.E., Savastinuk, L.C. (2006). Library 2.0: service for the next-generation library, Library Journal [Online], Vol. 131 No. 14, 40-42, Retrieved on 10 January 2009 from http://www.libraryjournal.com/article/CA6365200.html

Coombs, K.A. (2007). Building a Library Web Site on the Pillars of Web 2.0, Computers in Libraries [Online], Vol. 27, No. 1, Retrieved on 10 January 2009 from http://www.infotoday.com/cilmag/jan07/Coombs.shtml

Curran, K., Murray, M. and Christian, M. (2007). Taking the information to the public through Library 2.0, Library Hi Tech, Vol. 25, No. 2, 288-297.

Foo, S., Wee K.W. and Ng,Y. (2008). Library 2.0, Libraries and Library School [Unpublished Report], Retrieved on 10 January 2009 from http://www.las.org.sg/pa_sfjn.pdf

Hanson-Baldauf, D. and Hughes Hassell, S. (2009). The information and communication technology competencies of students enrolled in school library media certification programs. Library \& Information Science Research, Vol. 31, No. 1, 3-11.

Lepik, A. (2007). Relationship marketing and Library 2.0: successful prospective partnership? Signum, Vol. 40, No. 5, 13-16.

Lietzau, Z. (2008). U.S. Public Libraries and Web 2.0 [Presentation], Library Research Service, Denver, Colorado, Retrieved on $10 \quad$ January 2009 from http://www.lrs.org/documents/web20/pub_libs_web_20_ppt.pdf

Maness, J.M. (2006). Library 2.0 Theory: Web $\overline{2} .0$ and Its Implications for Libraries, Webology [Online], Vol. 3, No. 2, Retrieved on 10 January 2009 from http://www.webology.ir/2006/v3n2/a25.html

Orehovacki, T., Konecki, M. and Radosevic, D. (2008). Web 2.0 technologies in university education. Proceedings of the 31st MIPRO International Convention on Computers in Education,

Rijeka, Croatia: Croatian Society for Information and Communication Technology, Electronics and Microelectronics, 2008. 269-273

Stephens, M. and Collins, M. (2007). Web 2.0, Library 2.0, and the Hyperlinked Library, Serials Review, Vol. 33, No. 4, 253-256.

Titangos, H.-L. H. and Mason, G.L. (2009). Learning Library 2.0: 23 Things @SCPL, Library Management, Vol. 30, No. 1/2, 44-56.

Wang, M.Y. (2007). Introducing CRM into an academic library, Library Management, Vol. 28, No. 6/7, 281-291. 